\title{
Healthcare Resource Utilization for Oral Anticoagulant Reversal Therapies in Non-Valvular Atrial Fibrillation/Venous Thromboembolism Patients
}

\author{
Alex C. Spyropoulos ${ }^{\mathrm{a}, \mathrm{b}, \mathrm{e}}$, Briain O. Hartaigh ${ }^{\mathrm{c}}$, Zhun Cao ${ }^{\mathrm{d}}$, Craig Lipkin ${ }^{\mathrm{d}}$, Scott B. Robinson ${ }^{\mathrm{c}, \mathrm{d}}$, \\ Harjeet Caberwalc, Michaela Petrinic ${ }^{\mathrm{c}}$, Cheng Wang ${ }^{\mathrm{c}}$
}

\begin{abstract}
Background: The objective of the study was to describe the healthcare resource utilization (HCRU) and associated costs with hospitalized patients receiving specific versus non-specific oral anticoagulation reversal therapy for life-threatening bleeds and emergency surgeries or urgent procedures.
\end{abstract}

Methods: This retrospective observational study using the Premier Healthcare Database included adult patients aged $\geq 18$ years treated with idarucizumab (IDA) or 3- or 4-factor prothrombin complex concentrates (PCC) to reverse the effects of dabigatran or warfarin, respectively, between October 2015 and February 2018.

Results: Median ages for IDA $(\mathrm{n}=1,232)$ and PCC $(\mathrm{n}=4,939)$ patients were 78 and 74 years $(\mathrm{P}<0.001)$, respectively. IDA patients had lower bleeding and stroke risk assessment scores (HAS-BLED; $\mathrm{P}<0.001$ and $\mathrm{CHA}_{2} \mathrm{DS}_{2}$-VASc; $\mathrm{P}=0.014$ ) and lower prevalence of comorbidities compared with PCC patients. Median hospital length of stay was 6 and 7 days for patients who received IDA or PCC (P $<0.001)$, respectively. The percentage of patients with an intensive care unit (ICU) admission was lower for IDA patients compared with PCC patients $(61.3 \%$ vs. $68.7 \%$; $\mathrm{P}<0.001)$. Median total costs per hospitalization were $\$ 19,357$ for IDA patients and \$26,920 for PCC patients $(\mathrm{P}<0.001)$. Median costs per hospitalization for IDA and PCC treatment were $\$ 3,277$ and $\$ 4,424$, respectively. When HCRU and costs were examined by cause of reversal and type of bleed, similar trends in hospitalized costs emerged for IDA compared with PCC treatment.

Manuscript submitted September 22, 2021, accepted November 18, 2021 Published online January 10, 2022

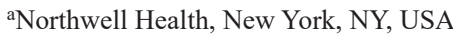

bDepartment of Obstetrics and Gynecology, I.M. Sechenov First Moscow State Medical University, Moscow, Russia

'Boehringer Ingelheim Pharmaceuticals, Inc., Ridgefield, CT, USA

dPremier, Inc., Charlotte, NC, USA

${ }^{e}$ Corresponding Author: Alex C. Spyropoulos, Institute for Health Innovations and Outcomes Research, Feinstein Institutes for Medical Research, Department of Medicine, Anticoagulation and Clinical Thrombosis Services, Northwell Health at Lenox Hill Hospital, New York, NY 10075, USA.

Email: Aspyropoul@northwell.edu

doi: https://doi.org/10.14740/cr1307
Conclusions: This analysis revealed lower HCRU and total hospital costs in patients administered IDA compared with PCC for reversal of oral anticoagulation, though differences in population characteristics and bleeding events were observed that may have contributed to these findings.

Keywords: Atrial fibrillation; Anticoagulation; Reversal of anticoagulation; Healthcare resource utilization and costs; Idarucizumab; Prothrombin complex concentrate; Dabigatran; Warfarin

\section{Introduction}

Thromboembolic events in patients with non-valvular atrial fibrillation (NVAF) or venous thromboembolism (VTE) are associated with significant morbidity, mortality, and increased healthcare resources and costs [1]. In 2010, 20\% of all nonhemorrhagic strokes among an estimated 2.7 to 6.1 patients with AF in the United States were related to the embolic risk of left atrial clot formation $[2,3]$. Strokes related to AF are more disabling, more likely to recur, and have a higher death rate than strokes unrelated to $\mathrm{AF}$ [1], and associated with significant costs for insurance payers and health systems [4-11].

Until 2010, warfarin had been the mainstay and sole oral anticoagulant available in the USA for stroke prevention in AF and treatment of VTE. Warfarin use carries the risk of increased bleeding related to numerous food and drug interactions and a narrow therapeutic range. Its dosing requires close follow-up of patients with frequent international normalized ratio monitoring [12-14]. In the event of acute major bleeding, warfarin's antidote vitamin $\mathrm{K}$ is not efficacious in this clinical setting, and initiation of prothrombin complex concentrates (PCC) and/or fresh frozen plasma (FFP) is essential for the urgent reversal of acquired coagulation factor deficiency $[15,16]$.

Since 2010, non-vitamin K oral anticoagulants (NOAC) have become available with a direct goal to inhibit the coagulatory cascade. Dabigatran (Pradaxa ${ }^{\circledR}$, Boehringer Ingelheim), a direct thrombin (factor II) inhibitor, is an NOAC approved by the US Food and Drug Administration to mitigate the risk of stroke and systemic embolism in patients with NVAF and treatment of VTE [17, 18]. Since 2015, idarucizumab (IDA, Praxbind ${ }^{\circledR}$, Boehringer Ingelheim) has become available as the 

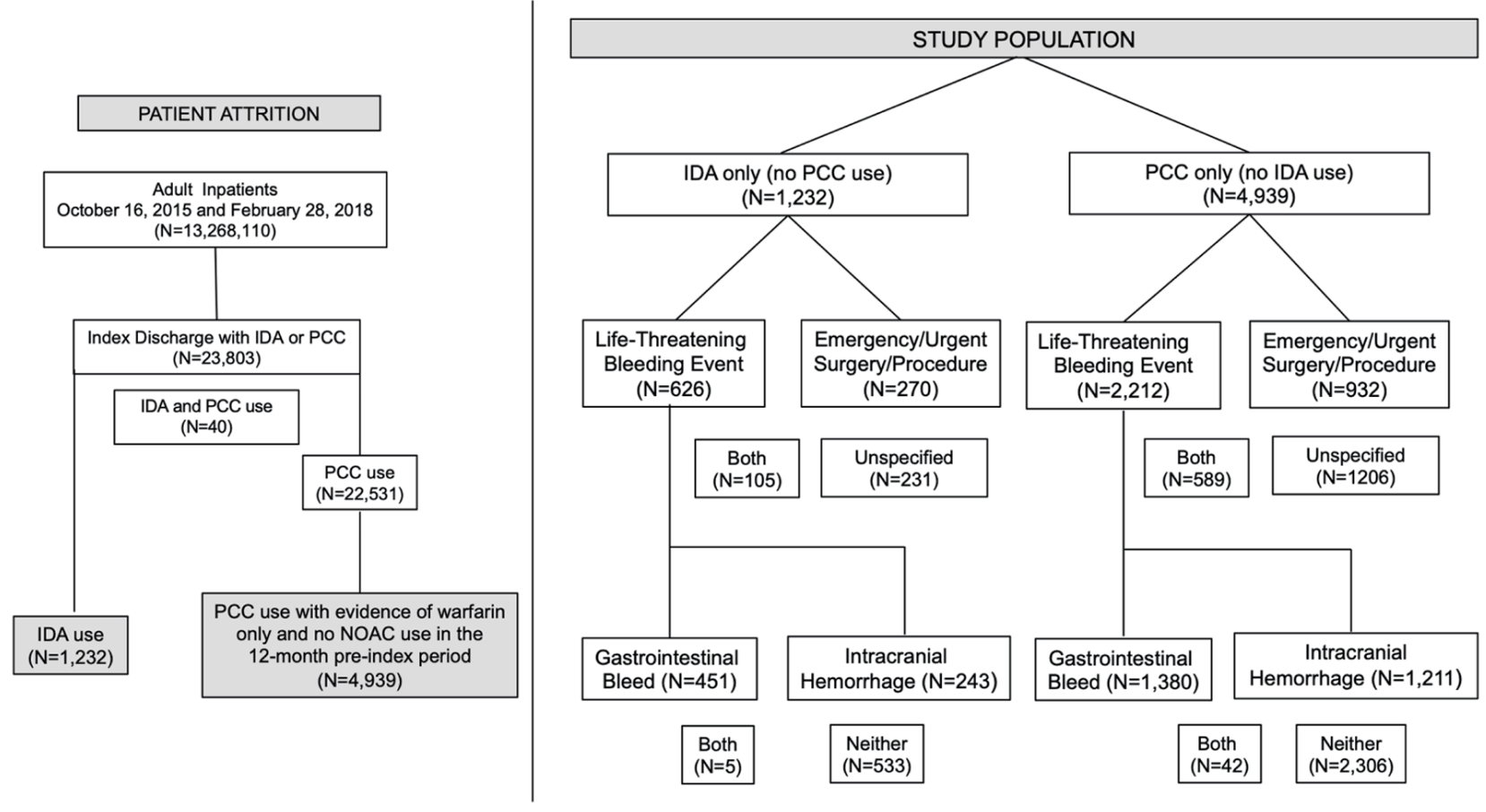

Figure 1. Patient attrition schematic and overall study population as well as the study population stratified by indication for oral anticoagulation reversal and type of bleed.

specific reversal anticoagulant agent for dabigatran [19].

To date, the extant literature comparing NOACs and VKAs has typically focused on bleeding risk [20-22]. To that end, few studies have directly assessed inpatient management of bleeding with IDA and PCC treatment for reverse anticoagulation of dabigatran and warfarin, respectively. This real-world study therefore utilized a hospital administrative database to address this gap and descriptively examine patient and clinical characteristics, as well as healthcare resource utilization (HCRU) and costs associated with reversal treatment among NVAF and VTE patients prescribed dabigatran and warfarin, who were admitted to hospital for life-threatening bleeds and/or emergency surgery or urgent procedures.

\section{Materials and Methods}

\section{Study design and data source}

This retrospective observational study used the Premier Healthcare Database (PHD) to describe patients receiving IDA or PCC as reversal therapy for oral anticoagulation with dabigatran or warfarin, respectively, during inpatient hospitalizations and to evaluate hospital HCRU and costs in those patients.

The PHD is a large geographically diverse administrative database consisting of non-profit, non-governmental and community and teaching hospitals and health systems from rural and urban areas throughout the USA [23]. This database represents approximately $25 \%$ of all admissions in the USA. The
PHD contains information on patient, hospital and visit characteristics, diagnosis and procedure codes, as well as costs for billed services. The PHD is considered exempt from Institutional Review Board oversight as dictated by Title 45 Code of Federal Regulations, Part 46 of the USA, specifically 45 CFR 46.101(b)(4). In accordance with the HIPAA Privacy Rule, disclosed data from the PHD are considered de-identified per 45 CFR 164.506(d)(2)(ii)(B) through the "Expert Determination" method.

\section{Study population}

Patients aged $\geq 18$ years who had any inpatient hospitalization with an International Classification of Diseases, Ninth and Tenth Revisions, Clinical Modification (ICD-9/10-CM) Diagnosis Code for NVAF (ICD-9 427.3x; ICD-10 I48) and/or VTE (DVT: ICD-9 451-453; ICD-10 I82.4x, I82.5x, I82.6x, I82.7x; PE: ICD-9 415.x; ICD-10 I26.x) in any position who were discharged between October 16, 2015 and February 28, 2018 with evidence of IDA or PCC (3-factor, Profilnine $^{\circledR}$; 4-factor, Kcentra ${ }^{\circledR}$; activated 4-factor, FEIBA; and unspecified) use for oral anticoagulation reversal of dabigatran (Pradaxa ${ }^{\circledR}$, Boehringer Ingelheim) or warfarin, respectfully, were included in the study. These inpatients were stratified by cause of reversal (life-threatening bleeds, defined as a major bleed based on an ICD-9-CM and ICD-10-CM diagnosis code for intracranial hemorrhage (ICH), gastrointestinal bleed (GIB), other bleed, or with evidence of blood transfusion, and with an emergency admission to the hospital, or with evidence of emergency room or intensive care unit (ICU) stay within 
1 day of the inpatient admission); emergency surgery/urgent procedure, defined as the presence of Medicare SeverityDiagnosis Related Group (MS-DRG) surgical code in combination with an emergency/urgent admission, or emergency room or ICU use on the first day of admission; and unspecified, defined as with no evidence of life-threatening bleeds or emergency surgery/urgent procedures) and type of major bleed (GIB and/or ICH, and undetermined) (Fig. 1). The first hospitalization with use of IDA or PCC was defined as the index hospitalization. The first date of receipt of IDA or PCC was used as the treatment index date. A 12-month pre-index period from the qualifying hospitalization captured prior warfarin and NOAC use during a hospitalization. Patients receiving PCC without evidence of hospital-based warfarin use, or with evidence of NOAC use in the hospital setting within the 12-month pre-index period were excluded from the study. $\mathrm{Pa}-$ tients receiving both IDA and PCC during the hospitalization period also were excluded.

\section{Study variables}

The exposure variable was the anticoagulation reversal treatment with IDA versus PCC in the hospitalized NVAF and VTE study population.

\section{Patient, visit, and hospital characteristics}

Patient demographics assessed age, sex, race/ethnicity, and healthcare insurer. Visit characteristics captured type of hospital admission. Urban and rural populations served, teaching status, geographical US census division, and bed capacity of the hospitals contributing data during the study were also reported.

\section{Clinical characteristics}

Deyo-modified Charlson Comorbidity Index (CCI) scores at index were reported to assess overall health status of patients [24, 25]. HAS-BLED (Hypertension, Abnormal Renal/Liver Function, Stroke, Bleeding History or Predisposition, Labile International Normalized Ratio, Elderly, Drugs/Alcohol) score was included for the assessment of bleeding risk [26, 27]. $\mathrm{CHA}_{2} \mathrm{DS}_{2}-\mathrm{VASc}$ schema (Congestive heart failure, Hypertension, Age $\geq 75$ Years, Diabetes mellitus, prior Stroke or transient ischemic attack, Vascular disease, Age 65 - 74 years, Sex category) was used to assess the thromboembolic risk [26, 28]. Comorbidities captured during the index hospitalization included GIB; ICH; coronary artery disease (CAD); peripheral artery disease (PAD); myocardial infarction (MI); congestive heart failure (CHF); chronic kidney disease (CKD); acute kidney failure cirrhosis/hepatitis; hypertension; dyslipidemia; diabetes mellitus; chronic obstructive pulmonary disease (COPD); history of cancer; ischemic stroke/transient ischemic attack (TIA); coronary artery bypass grafting (CABG), other open-heart surgery; percutaneous coronary intervention (PCI); other closed cardiac procedures; history of falls; dementia; and depression/anxiety. Administration of tissue plasminogen activator (tPA) to prevent an ischemic or thrombotic event in patients undergoing an emergency surgery or urgent procedure and restart of oral anticoagulation during the index hospitalization also were determined.

\section{Outcomes}

Utilization and costs of supportive care such as blood component use, blood transfusions, and hemodialysis [29] were included in the study. HCRU and costs related to IDA and PCC treatments were assessed. These included inpatient length of stay (LOS), total cost as reported by the hospitals, the proportion of ICU admissions, ICU LOS, and costs associated with other HCRU. Costs specific to IDA and PCC use were also examined.

\section{Statistical analysis}

The present study employed an unadjusted descriptive approach to characterize the overall IDA and PCC patient populations, as well as HCRU and related costs. Given the nonnormal distribution of most continuous variables, central tendency measures used were median and 25th - 75th percentile with mean reported for those where the median and 25 th - 75th were the same value to describe the spread of the data. Categorical data are expressed as counts with percentages. Bivariate analyses are used to provide comparisons between the treatment cohorts. Due to the non-normal distribution of the study variables, Wilcoxon rank-sum tests assessed differences in continuous variables between IDA and PCC patients, and Chi-square tests examined differences in dichotomous or categorical variables. Although statistical tests were performed, the main purpose of this study is to better understand the two patient groups, rather than to draw a conclusion on whether group has lower HCRU and costs, therefore no statistical adjustment was performed. SAS 9.4 was used for the statistical analysis. A P-value of 0.05 or lower in a two-sided test was considered statistically significant.

\section{Results}

\section{Study population}

Among the 23,803 hospitalized adults who received IDA or PCC during the study period, 1,232 patients received IDA treatment, and 4,939 received PCC treatment during the index period as per Figure 1.

\section{Patient, visit, and hospital characteristics}

Table 1 presents patient, visit, and hospital characteristics. The IDA patients were older (median 78 years) compared with the PCC patients (median 74 years; $\mathrm{P}<0.001$ ). The proportion of 
Table 1. Patient, Visit, and Hospital Characteristics

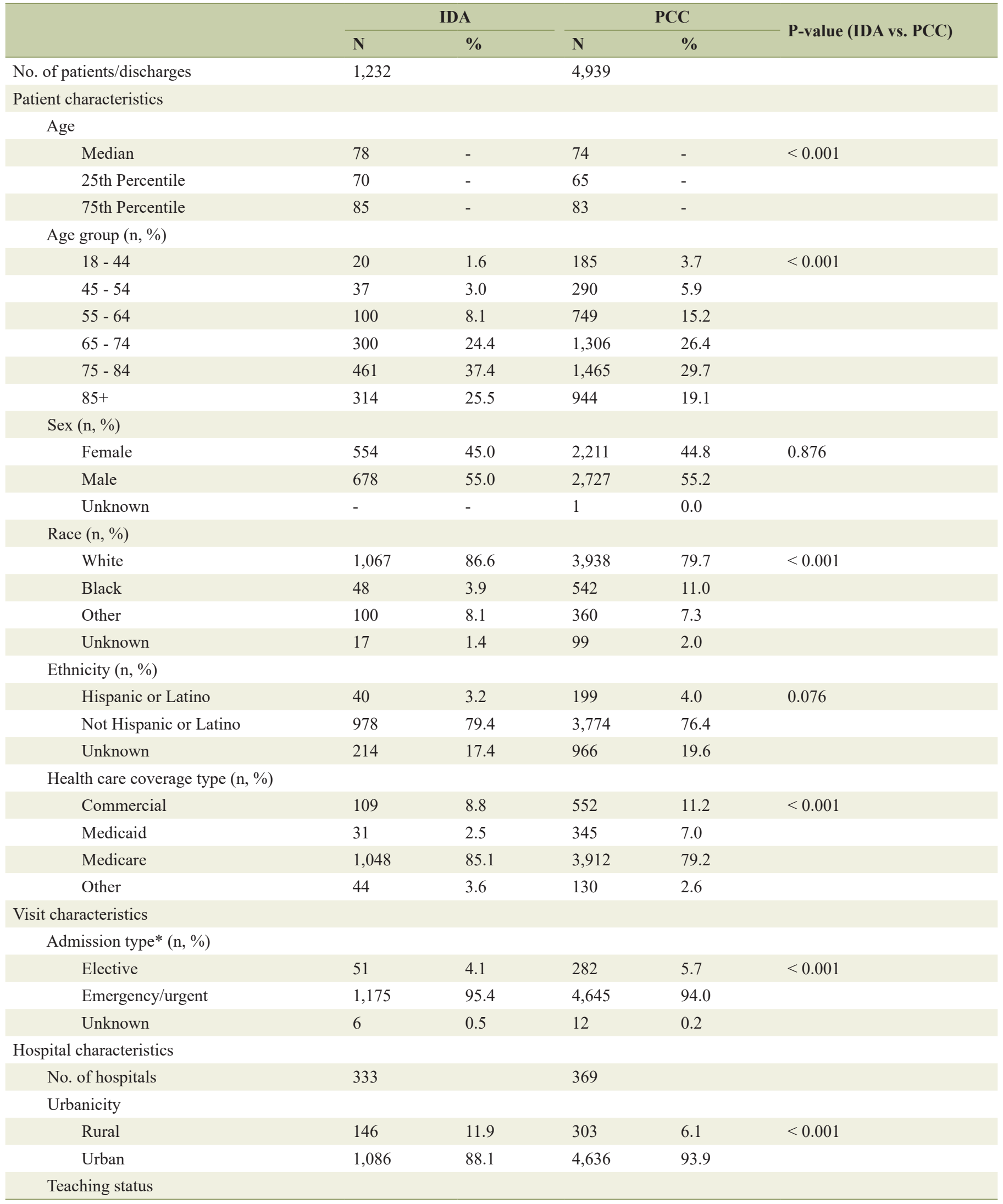


Table 1. Patient, Visit, and Hospital Characteristics - (continued)

\begin{tabular}{|c|c|c|c|c|c|}
\hline & \multicolumn{2}{|c|}{ IDA } & \multicolumn{2}{|c|}{ PCC } & \multirow{2}{*}{ P-value (IDA vs. PCC) } \\
\hline & $\mathbf{N}$ & $\%$ & $\mathbf{N}$ & $\%$ & \\
\hline Non-teaching & 665 & 54.0 & 2,059 & 41.7 & $<0.001$ \\
\hline \multicolumn{6}{|l|}{ US Census Division (n, \%) } \\
\hline East North Central & 136 & 11.0 & 977 & 19.8 & $<0.001$ \\
\hline Mountain & 14 & 1.1 & 98 & 2.0 & \\
\hline New England & 41 & 3.3 & 276 & 5.6 & \\
\hline Pacific & 175 & 14.2 & 731 & 14.8 & \\
\hline South Atlantic & 362 & 29.4 & 1,334 & 27.0 & \\
\hline$\leq 99$ & 47 & 3.8 & 99 & 8.4 & $<0.001$ \\
\hline $100-199$ & 124 & 10.1 & 324 & 6.6 & \\
\hline $200-299$ & 211 & 17.1 & 545 & 11.0 & \\
\hline $300-499$ & 372 & 30.2 & 1,396 & 28.3 & \\
\hline $500+$ & 478 & 38.8 & 2,575 & 52.1 & \\
\hline
\end{tabular}

*Patients included in the emergency/urgent group were those who were identified as having "emergency" or "urgent" type of admission or admitted from a Trauma Center. IDA: idarucizumab; PCC: prothrombin complex concentrates.

female and male patients was similar with $45.0 \%$ of IDA patients and $44.8 \%$ of PCC patients being female $(\mathrm{P}=0.876)$. A greater proportion of IDA patients were White compared with PCC patients $(86.6 \%$ vs. $79.7 \%$; $\mathrm{P}<0.001)$. Hispanic/Latino ethnicity accounted for $3.2 \%$ and $4.0 \%$ of the respective cohorts $(\mathrm{P}=0.076)$. Medicare was the primary payer for both treatment cohorts with a higher proportion of IDA patients enrolled in Medicare compared with PCC patients (85.1\% vs. $79.2 \%$; $\mathrm{P}<0.001)$. Regardless of reversal therapy, most admissions were of an emergency/urgent procedural nature. The proportion of IDA patients treated in urban $(88.1 \%$ vs. $93.9 \%)$ and teaching hospitals $(46.0 \%$ vs. $58.3 \%)$ was significantly lower compared with PCC patients (each, $\mathrm{P}<0.001$ ). The geographic distribution of hospitals was significantly different between the patient cohorts $(\mathrm{P}<0.001)$ with IDA patients more likely to be treated in hospitals located in the South and Middle Atlantic divisions. IDA patients were more likely treated in hospitals with $<300$ beds, and PCC patients were more likely treated in hospitals with $\geq 500$ beds $(\mathrm{P}<0.001)$.

\section{Clinical characteristics}

Table 2 presents the clinical characteristics. Among IDA patients, 59.3\% experienced life-threatening bleeds compared with $56.7 \%$ in PCC patients $(\mathrm{P}=0.096)$. The percentage of patients with emergency surgeries or urgent procedures was similar (30.4\% IDA vs. $30.8 \%$ PCC, $\mathrm{P}=0.808)$. Fewer IDA patients had both a life-threatening bleed and an emergency surgery or urgent procedure than the PCC patients $(8.5 \%$ vs. $11.9 \% ; \mathrm{P}<0.001)$. IDA patients were more likely to have NVAF than PCC patients $(89.3 \%$ vs. $72.6 \%, \mathrm{P}<0.001)$, and less likely to have VTE (4.1\% vs. $8.7 \%, \mathrm{P}<0.001)$.

The CCI score in IDA patients was lower (median 2, 25th - 75th percentiles: 1 - 4) than PCC patients (median 4, 25th - 75th percentiles: 2 - 5; $\mathrm{P}<0.001)$. Although both IDA and PCC patients had a median HAS-BLED score of 3 (25th - 75th percentiles: 1 - 4), and a median $\mathrm{CHA}_{2} \mathrm{DS}_{2}$-VASc score of 4 (25th - 75th percentiles: 3 - 5), the mean HAS-BLED score for the IDA patients (2.6, standard deviation (SD): 1.6) was lower compared with PCC patients (mean 3.2, SD: 1.5; P < 0.001 ), and similarly, the mean $\mathrm{CHA}_{2} \mathrm{DS}_{2}$-VASc score for IDA patients was lower as compared with PCC patients (mean: 3.9, SD: 1.9 for IDA; mean: 4.1, SD: 1.9 for PCC; $\mathrm{P}=0.014)$, indicating that PCC patients in the fourth quartile had significantly higher HAS-BLED and $\mathrm{CHA}_{2} \mathrm{DS}_{2}$-VASc scores than IDA patients. The IDA patients had a lower prevalence of ICH (20.1\%, vs. $25.4 \% ; \mathrm{P}=0.001)$ but a higher prevalence of GIB (37.0\% vs. $28.8 \%$; $\mathrm{P}<0.001)$ compared with PCC patients. Further, IDA patients had a significantly lower prevalence of chronic conditions such as CAD, PAD, MI, CHF, CKD, hypertension, diabetes mellitus, COPD, CABG, other open-heart surgeries, and other closed cardiac procedures (all, $\mathrm{P}$ values $<$ $0.05)$. The prevalence of TIA was not statistically significant between cohorts.

For patients undergoing an emergency surgery or urgent 
Table 2. Clinical Characteristics




Table 2. Clinical Characteristics - (continued)

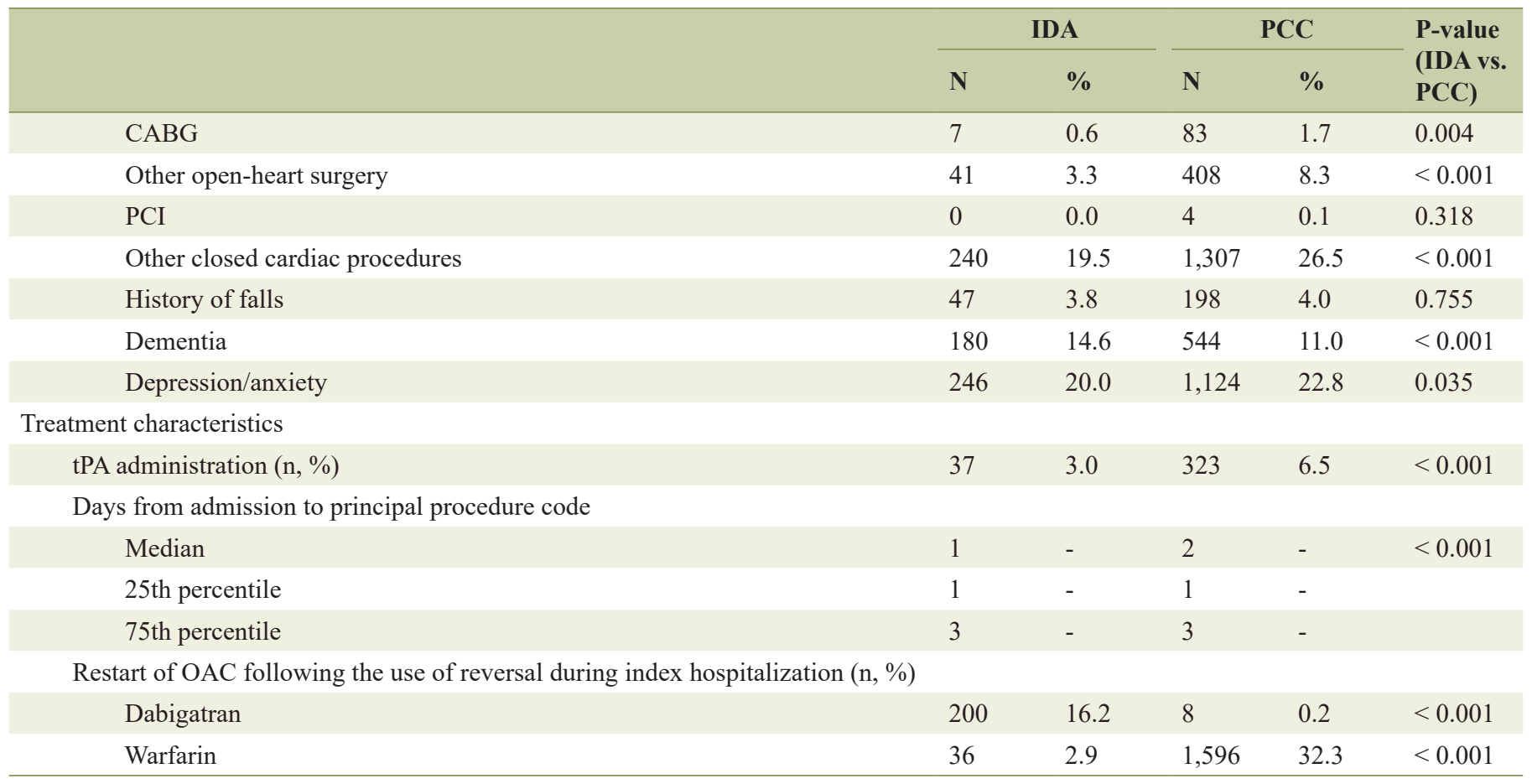

aA patient may have both NVAF and VTE diagnoses during the index hospitalization. IDA: idarucizumab; PCC: prothrombin complex concentrates; OAC: oral anticoagulant; NVAF: non-valvular atrial fibrillation; VTE: venous thromboembolism; DVT: deep vein thrombosis; PE: pulmonary embolism; CCI: Charlson Comorbidity Index; HAS-BLED: Hypertension, Abnormal Renal/Liver Function, Stroke, Bleeding History or Predisposition, Labile International Normalized Ratio, Elderly, Drugs/Alcohol; $\mathrm{CHA}_{2} \mathrm{DS}_{2}$-VASc: Congestive heart failure, Hypertension, Age $\geq 75$ Years, Diabetes mellitus, prior Stroke or transient ischemic attack, Vascular disease, Age 65 - 74 years, Sex category; CAD: coronary artery disease; PAD: peripheral artery disease; MI: myocardial infarction; CHF: congestive heart failure; CKD: chronic kidney disease; COPD: chronic obstructive pulmonary disease; TIA: ischemic stroke/transient ischemic attack; CABG: coronary artery bypass grafting; PCl: percutaneous coronary intervention; tPA: tissue plasminogen activator.

procedure, tPA use to prevent an ischemic or thrombotic event was less likely administered in the IDA cohort compared with the PCC cohort (3.0\% vs. $6.5 \%$; $<<0.001)$. During index hospitalization, dabigatran anticoagulation was restarted in $16.2 \%$ of patients treated with IDA. Warfarin was reinitiated in $32.3 \%$ of PCC-treated patients.

\section{HCRU and costs}

Table 3 outlines HCRU and costs associated with the oral anticoagulation reversal treatments. Only $0.6 \%$ of the IDA patients and $1.0 \%$ of the PCC patients received NovoSeven rFVIIa during the index hospitalization $(\mathrm{P}=0.638)$. Costs for this treatment were similar between the respective cohorts (median: $\$ 11,135,25$ th - 75th percentiles: $\$ 3,605$ - \$17,927 vs. median: $\$ 7,156,25$ th - 75th percentiles: $\$ 3,779$ - $\$ 14,848 ; \mathrm{P}=0.261$ ). IDA patients were less likely administered FFP than PCC patients $(17.8 \%$ vs. $34.8 \%$; $\mathrm{P}<0.001)$, with costs noted to be significantly lower (median $\$ 164,25$ th - 75th percentiles: $\$ 68$ - \$363 vs. median \$203, 25th - 75th percentiles: \$97 - \$421, respectively; $\mathrm{P}=0.011$ ) for IDA patients. The utilization and costs for cryoprecipitate and platelets were also lower in IDA patients. IDA patients compared with the PCC patients were more likely to receive packed red blood cells (PRBCs, 5.5\% vs. $3.0 \% ; \mathrm{P}<0.001)$, although respective costs were similar (median \$500, 25th - 75th percentiles: \$238 - \$867 vs. median $\$ 530,25$ th - 75th percentiles: $\$ 343$ - $\$ 955 ; \mathrm{P}=0.286)$. The IDA patients also incurred lower utilization and costs for volume expanders, fibrinogen, and albumin (all, $\mathrm{P}<0.05$ ). Transexamic acid use was minimal and costs were similar $(\mathrm{P}>0.05)$. Vitamin K use was significantly higher $(\mathrm{P}<0.001)$ in the PCC patients $(79.8 \%)$ than in the IDA patients $(10.1 \%, \mathrm{P}<0.001)$, although median costs did not differ $(\mathrm{P}>0.05)$. Pharmacy costs among IDA patients were lower (median \$4,793, 25th - 75th percentiles: $\$ 3,094$ - \$7,399) than among PCC patients (median \$7,039, 25th - 75th percentiles: \$4,281 - \$12,067; P $<0.001)$. Laboratory costs for IDA patients were also lower (median $\$ 605,25$ th - 75th percentiles: $\$ 348$ - \$1,130 vs. median $\$ 937,25$ th -75 th percentiles: $\$ 470-\$ 1,945 ; \mathrm{P}=0.036$ ). Only $3.6 \%$ of the IDA patients underwent hemodialysis during the index stay compared with $15.5 \%$ of the PCC patients $(\mathrm{P}<$ $0.001)$. Among IDA patients, the respective number of days on dialysis was fewer (median: 2 days, 25th - 75th percentiles: 1 4.5 vs. median 4 days, 25 th - 75th percentiles: 2 - 8; $\mathrm{P}<0.001)$, and respective costs trended lower (median $\$ 1,780,25$ th -75 th percentiles: $\$ 612$ - $\$ 3,926$ vs. median $\$ 2,285,25$ th - 75th percentiles: $\$ 942$ - $\$ 5,247 ; \mathrm{P}=0.060)$. 
Table 3. Resource Utilization and Cost Outcomes

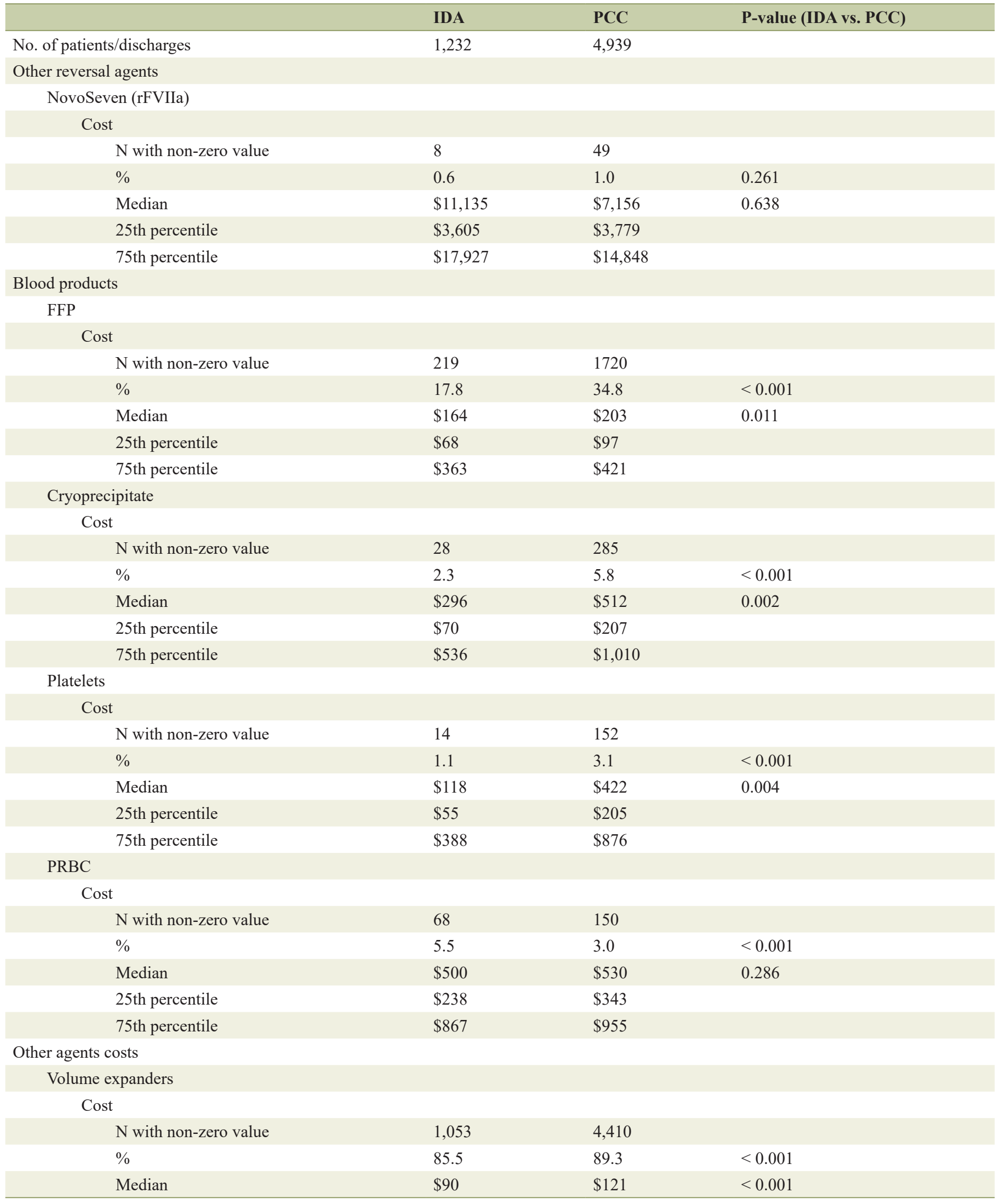


Table 3. Resource Utilization and Cost Outcomes - (continued)

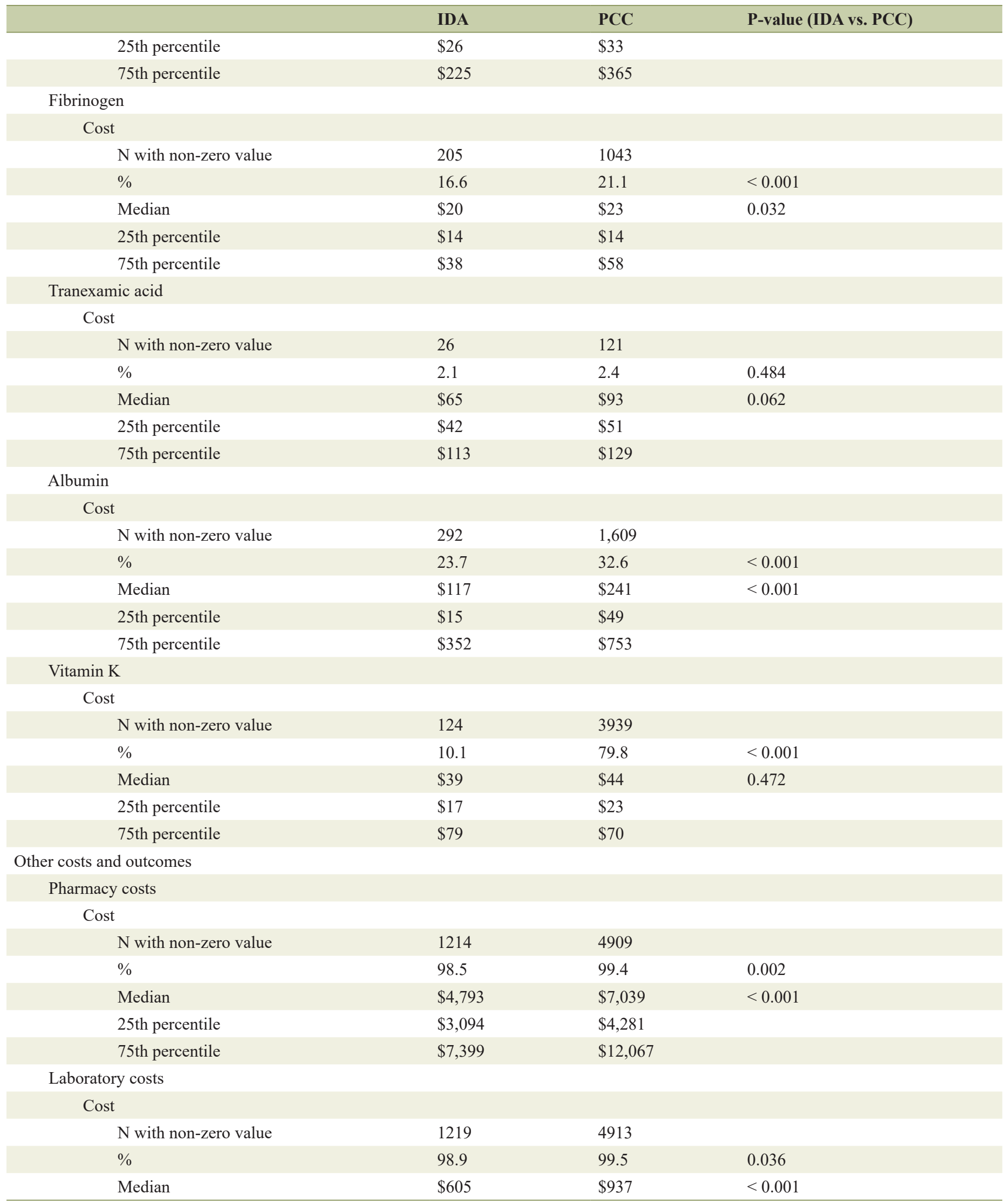


Table 3. Resource Utilization and Cost Outcomes - (continued)

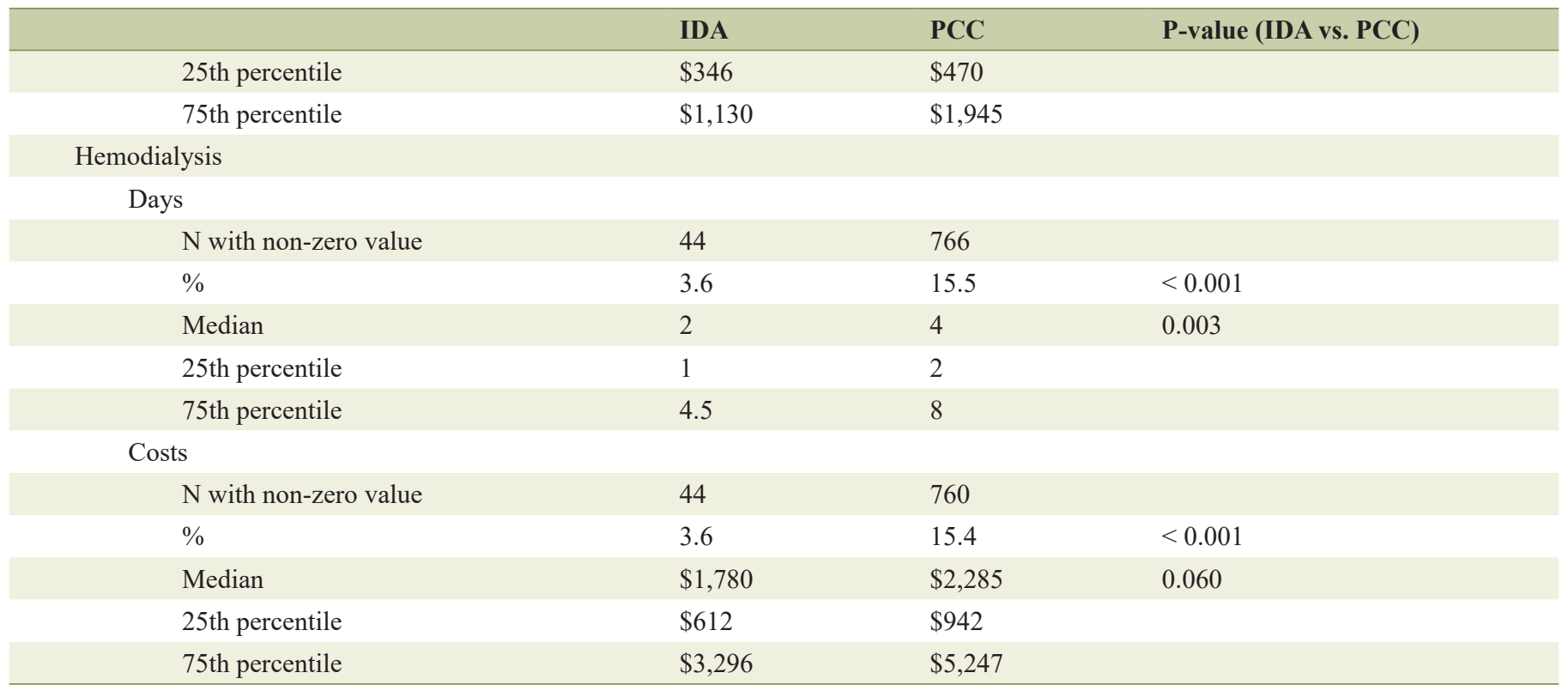

IDA: idarucizumab; PCC: prothrombin complex concentrates; FFP: fresh frozen plasma; PRBC: packed red blood cells.

\section{LOS and cost outcomes}

Table 4 summarizes hospital and ICU LOS and costs, including costs for the oral reversal agents. The IDA patients had a shorter total LOS compared with PCC patients (median 6 days, 25th - 75th percentiles: 3 - 9 vs. median 7 days, 25th -75 th percentiles: 4 - 14; $\mathrm{P}<0.001)$. The LOS from index treatment date to discharge was also shorter (median 5 days, 25 th -75 th percentiles: 3 - 5 vs. median 6 days, 25th - 75th percentiles: 3 - 11, respectively; $\mathrm{P}<0.001)$. The percentage of patients with an ICU admission was lower for IDA patients compared with PCC patients $(61.3 \%$ vs. $68.7 \%$; $\mathrm{P}<0.001)$. The median ICU LOS was 1 day for IDA patients (25th - 75th percentiles: 0 - 3) compared with 2 days for PCC patients (25th - 75th percentiles: 0 - 5) $(\mathrm{P}<0.001)$. The median total index hospitalization costs for IDA patients was $\$ 19,357$ (25th - 75th percentiles: $\$ 12,461$ - $\$ 33,490)$ compared with $\$ 26,920$ (25th - 75th percentiles: $\$ 16,125$ - \$50,901) for PCC patients $(\mathrm{P}<0.001)$. Notably, the median cost of treatment specific to IDA was $\$ 3,277$ (25th - 75th percentiles: $\$ 1,885$ - \$4,984), while the median cost of treatment specific to PCC was $\$ 4,424$ (25th - 75th percentiles: $\$ 2,540$ - $\$ 7,404)$.

\section{Outcomes by indication and type of bleed}

Table 5 summarizes HCRU and costs by reversal indication and bleed type. When stratified by life-threatening bleeds, emergency surgery or urgent procedures, both causes, or an unspecified cause, compared with PCC patients, IDA patients generally displayed a shorter total hospital LOS, ICU LOS, a lower percentage of ICU admissions, and lower total costs within most strata. The one exception being that the percent- age of patients with an ICU admission did not differ appreciably between both cohorts within the subset of patients with a life-threatening bleed only. When further stratified by specific type of bleed, among patients with a GIB, ICH, and those without either bleed, the total hospital LOS, ICU LOS, and total index hospitalization costs were lower in IDA patients compared with PCC patients (all $\mathrm{P}<0.05$ ), with the exception that the percentage of patients with an ICU admission was not statistically different between IDA and PCC in patients with GIB only.

\section{Discussion}

Our study found that, when comparing a specific oral anticoagulant reversal strategy for dabigatran with IDA versus a nonspecific reversal strategy for warfarin with PCC and stratified by type and urgency of bleed as well as emergency or urgent procedure or surgery, there appeared to be less resource utilization in the IDA cohort, both in terms of lower HCRU and total hospital costs. Our study, however, did find differences in the population and bleeding characteristics of those using chronic oral anticoagulant therapy that may have accounted for some of these findings.

In the past decade, NOAC prescribing has increased in NVAF and VTE patients. Findings from a large healthcare system showed that between 2010 and mid-2013, 28\% of NVAF patients received an NOAC and $72 \%$ received warfarin. Between late-2013 and mid-2019, the ratio was reversed with $77 \%$ receiving NOACs and $23 \%$ receiving warfarin [30]. In light of the increased uptake of NOAC use, to the best of our knowledge, there appears to be no literature that has examined HCRU and associated costs in non-specific anticoagulant reversal strategies for warfarin versus dabigatran-reversal by 
Table 4. Length of Stay and Cost Outcomes

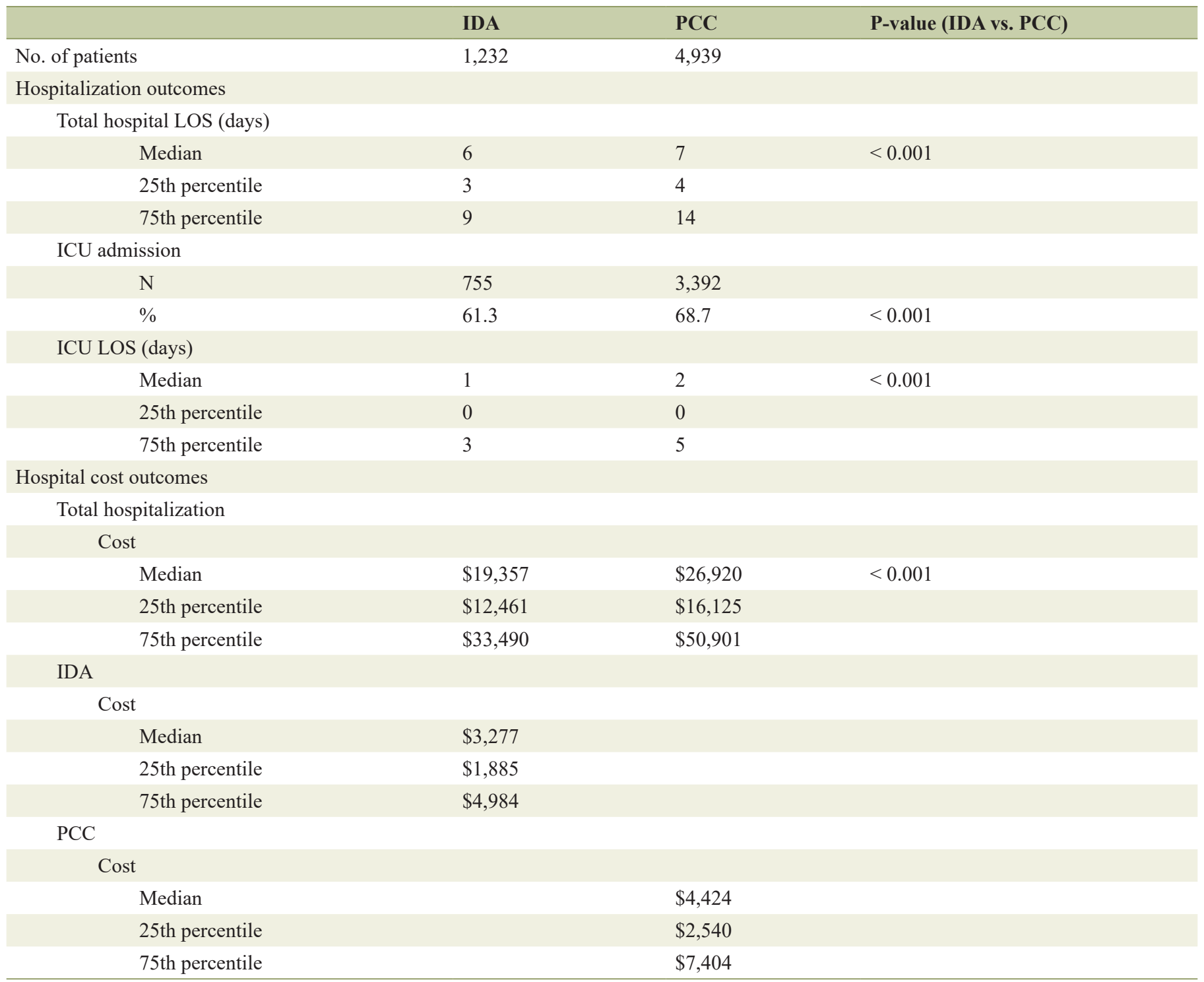

IDA: idarucizumab; PCC: prothrombin complex concentrates; LOS: length of stay; ICU: intensive care unit.

IDA [31, 32]. This study presents a unique real-world evidence perspective towards understanding the HCRU and costs in those patients using a geographically diverse, all-payer database. The findings from the present study demonstrate that IDA-treated patients displayed lower HCRU and costs compared with PCC treated patients, and these findings remained consistent when patients were stratified by indication for reversal therapy and type of bleed.

There are several potential explanations as to why lower HCRU and costs were observed among IDA treated patients. IDA is a humanized monoclonal antibody fragment that is a specific antidote which has a binding affinity about 350 times greater than the binding affinity of dabigatran for thrombin [33]. It rapidly and effectively reverses anticoagulant activity by neutralizing both free and thrombin-bound dabigatran [34]. In addition, due to the low protein binding of dabigatran, he- modialysis offers another means to remove active dabigatran from the circulation [29]. Dabigatran also compared to warfarin has predictable pharmacokinetics and pharmacodynamics, including a short plasma half-life and high renal clearance [34]. Hence, the efficacy of IDA reversal treatment may have likely been a factor in the shorter hospital stays and lower hospital costs as documented in this study.

In addition, patients with chronic comorbidities that are more likely to receive dose-adjusted warfarin for chronic oral anticoagulation and, thus, necessitate a PCC-based reversal strategy, may drive up the cost for the PCC-treated patients. In our study, we observed that IDA patients were older, but presented with lower CCI, HAS-BLED, and $\mathrm{CHA}_{2} \mathrm{DS}_{2}$-VASc scores, a lower prevalence of other chronic conditions, and were less likely to have undergone any cardiovascular procedure compared to patients on warfarin reversed with PCC. 


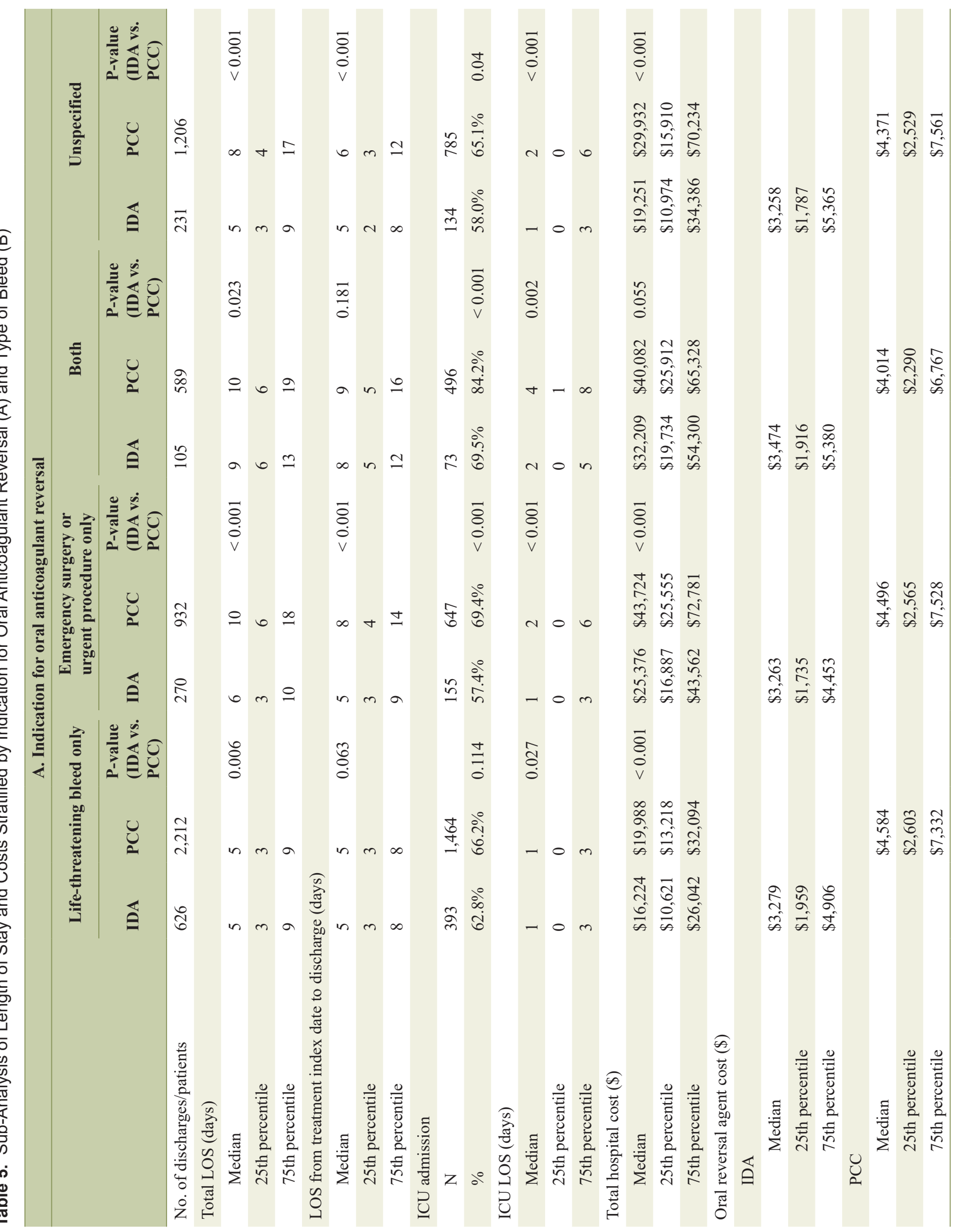




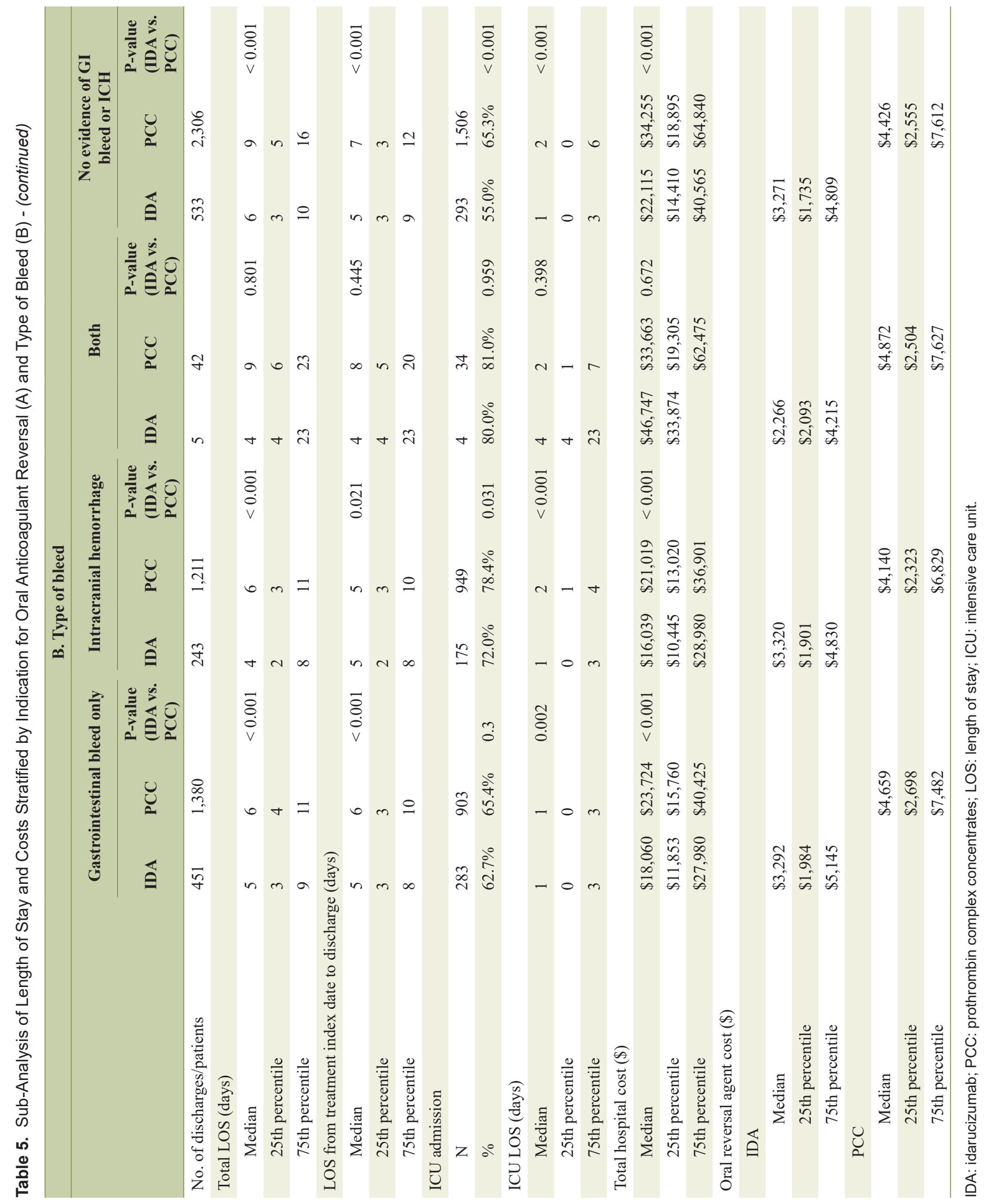


Brownell and colleagues also found that the shift toward increased NOAC use was documented in patients of advanced age and with a history of a major bleed [30]. Conversely, patients who presented with CAD, renal dysfunction and/or diabetes mellitus were more likely to be treated with warfarin [30].

Further in comparison to warfarin, while NOACs are known to heighten the risk for a GIB, these events are most often rarely fatal. In contrast, the use of NOACs tends to offset the risk of experiencing an $\mathrm{ICH}$, which are more commonly fatal [35]. This study confirmed that a higher proportion of patients on dabigatran treated with IDA had a GIB, while a higher proportion of patients on warfarin treated with PCC patients had an $\mathrm{ICH}$, indicating a key difference between the two groups of patients. Treatment for an $\mathrm{ICH}$ is generally more costly than a GIB and usually involves more intensive healthcare resource use and a longer hospital stay, which could be another factor owing to the higher costs observed in the PCC group. However, in our study, even within the subgroup of patients treated for ICH, IDA patients incurred lower costs (median: $\$ 16,039$ vs. $\$ 21,019 ; \mathrm{P}<0.001$ ) and shorter LOS (median: 4 days vs. 6 days; $\mathrm{P}<0.001$ ) compared with the PCC patients, indicating that the difference in the proportion of patients with an $\mathrm{ICH}$ may not reflect the primary reason for increasing the total costs in the PCC patients.

Notably, drug and supportive care costs were all lower in the IDA patients. The median cost of IDA was $\$ 3,277$ per hospital stay compared with $\$ 4,424$ for PCC use. In addition, PCC treatment is commonly combined with the use of vitamin $\mathrm{K}$ to prevent rebound anticoagulation [36] and/or FFP to exogenously replace factor II, IX, X, and XII [37]. Among PCC patients in this study, $79.8 \%$ received concomitant vitamin $\mathrm{K}$, whereas only $10.1 \%$ of IDA patients received vitamin $\mathrm{K}$. Almost 35\% of PCC patients also received FFP, which was two-fold higher compared with the IDA patients. To that end, the costs of concurrent vitamin K or FFP administration, as well as potential complications or adverse events associated with vitamin K excess and FFP use [36] may represent other contributing factors driving higher costs that were incurred in the PCC patient group.

Several limitations were present in this investigation that warrant further discussion. As in all administrative databases, the clinical conditions were identified by diagnosis or procedure codes; therefore the accuracy relied on the correct coding by the hospitals. Our study was a retrospective study using a large database of hospitalized patients on chronic oral anticoagulant therapy for NVAF and VTE indications, that was designed to describe the characteristics of the populations receiving IDA for the reversal of dabigatran versus PCC for the reversal of VKA and to examine hospital resource use and costs. In order to ascertain any differences in the IDA and PCC populations, statistical adjustment was not employed. Nonetheless, absence of statistical adjustments for differences in demographic and clinical characteristics observed between the IDA and PCC treatments created a potential selection bias. Some clinical factors such as laboratory test results were not available in our hospital administrative database, limiting further assessment on the patients' severity level as well as information regarding coagulation monitoring. Assessment of the 12-month pre-index period to ensure no prior NOAC use in the warfarin cohort depended on a prior visit to the same index hospital, so patients with NOAC use in a different hospital or at home may have been included in the PCC cohort. The inclusion of patients who did not respond well to NOACs and switched to warfarin in the pre-index period may introduce potential upward bias in the estimates of costs and utilization in the PCC patient group. We also could not discount unobservable confounders between the study populations that may account for the HCRU and hospital cost differences between the two groups. Furthermore, as IDA is the specific reversal therapy to dabigatran, the findings from this study should not be generalized to all NOAC reversal agents. Finally, given the higher price of dabigatran, the total cost associated with the oral anticoagulant use may not be lower in the dabigatran treated patients, when compared with those who received warfarin.

Despite some limitations, these findings represent the first large real-world evidence study of prescribing practices to reverse anticoagulation with IDA and PCC for dabigatran and warfarin, respectively. Our study findings suggest a lack of adherence to NOAC reversal guidelines. For example, although guidelines state that vitamin $\mathrm{K}$ should not be administered to IDA patients [38], our study found $10.1 \%$ of the IDA patients had evidence of vitamin $\mathrm{K}$ use. Although excluded from the study analysis presented herein, some patients received both PCC and IDA. Most notably, the present study appears to represent the first of its kind to assess HCRU and costs by reversal therapy and not by anticoagulant use [31]. A Canadian study published in 2020, assessed healthcare utilization and costs among atrial fibrillation (AF) patients with NOAC- and warfarin-related major bleeding requiring hospitalization between 2010 and 2015, but did not examine the effect of reversal therapy [32]. In the absence of an NOAC antidote to reverse bleeding, adjusted blood product costs were higher for the NOACs than for warfarin patients. Otherwise, patient characteristics were similar and adjusted analysis for LOS, ICU admissions, and direct medical costs were also similar between the cohorts. Leveraging the findings from $\mathrm{Xu}$ et al [32] as a baseline, the results from this study indicated that the use of IDA had a significant effect reducing HCRU and costs in patients with prior dabigatran use.

\section{Conclusions}

This study was undertaken to provide real-world evidence on the differences in patient characteristics, clinical conditions, and overall resource use and costs between patient receiving IDA for the reversal of dabigatran and those receiving PCC for the reversal of warfarin IDA, the first approved NOAC antidote to reverse dabigatran anticoagulation, demonstrated lower resource utilization and costs as compared with PCC use for warfarin reversal. These findings were consistent irrespective of the cause for reversal or the type of bleeding episode experienced. Although, it bears mentioning that the lower overall disease severity found in the IDA cohort compared with the PCC cohort may have influenced study findings in the absence of an adjusted analysis, the findings from this study represent the first large real-world evidence study of prescribing practices to 
reverse anticoagulation. To that end, forthcoming studies are needed to support the contention that IDA may help mitigate HCRU and costs incurred among patients with NVAF or VTE who require IDA for reverse anticoagulation of dabigatran.

\section{Acknowledgments}

Carol Cohen, senior medical writer formerly employed by Premier Applied Sciences, Premier Inc. provided writing, editing, and publication support. Cate Polacek, senior medical writer employed by Premier Applied Sciences, Premier Inc. provided editing and publication support. Parts of study findings were presented in Quality of Care and Outcomes Research (QCOR) 2019 and Society for Academic Emergency Medicine (SAEM) 2020 conferences as poster presentations.

\section{Financial Disclosures}

A.C. Spyropoulos serves as a consultant on the study, and received consulting fee from Boehringer Ingelheim. B. O. Hartaigh, H. Caberwal, M. Petrini and C. Wang are employees of Boehringer Ingelheim. Z. Cao and C. Lipkin are employees of Premier Applied Sciences, Premier Inc., which received payment from Boehringer Ingelheim Pharmaceuticals, Inc. to conduct the study. S. Robinson was a former employee of Premier Inc. at the time that the study was conducted.

\section{Conflict of Interest}

The authors report no conflict of interest. SBR was employed by Premier, Inc. at the time the study was conducted.

\section{Informed Consent}

Not applicable.

\section{Author Contributions}

A.C. Spyropoulos, B.O. Hartaigh, and Z. Cao are responsible for design of the study. Z. Cao and C. Lipkin have full access to all the data in the study and take responsibility for the integration of the data and accuracy of the data analysis. A.C. Spyropoulos, B.O. Hartaigh, and Z. Cao interpreted the study findings with assistance from C. Lipkin. Z. Cao drafted the first draft of the manuscript. All authors were responsible for critical revision of the manuscript, for important intellectual content, and provided approval of the final draft.

\section{Data Availability}

Any inquiries regarding supporting data availability of this study should be directed to the corresponding author.

\section{Abbreviations}

AF: atrial fibrillation; CABG: coronary artery bypass grafting; CAD: coronary artery disease; CCI: Charlson Comorbidity Index; $\mathrm{CHA}_{2} \mathrm{DS}_{2}$-VASc: Congestive heart failure, Hypertension, Age $\geq 75$ Years, Diabetes mellitus, prior Stroke or transient ischemic attack, Vascular disease, Age 65 - 74 years, Sex category; CHF: congestive heart failure; CKD: chronic kidney disease; COPD: chronic obstructive pulmonary disease; DVT: deep vein thrombosis; FFP: fresh frozen plasma; GIB: gastrointestinal bleed; HAS-BLED: Hypertension, Abnormal Renal/ Liver Function, Stroke, Bleeding History or Predisposition, Labile International Normalized Ratio, Elderly, Drugs/Alcohol; HCRU: healthcare resource utilization; ICD: International Classification of Diseases; ICH: intracranial hemorrhage; ICU: intensive care unit; IDA: idarucizumab; LOS: length of stay; MI: myocardial infarction; NOAC: non-vitamin K oral anticoagulants; NVAF: non-valvular atrial fibrillation; PAD: peripheral artery disease; PCC: prothrombin complex concentrates; PCI: percutaneous coronary intervention; PE: pulmonary embolism; PHD: Premier healthcare database; TIA: ischemic stroke/transient ischemic attack; tPA: tissue plasminogen activator; VKA: vitamin K antagonist; VTE: venous thromboembolism

\section{References}

1. Alkhouli M, Noseworthy PA, Rihal CS, Holmes DR, Jr. Stroke prevention in nonvalvular atrial fibrillation: a stakeholder perspective. J Am Coll Cardiol. 2018; 71(24):2790-2801.

2. January CT, Wann LS, Alpert JS, Calkins H, Cigarroa JE, Cleveland JC, Jr., Conti JB, et al. 2014 AHA/ACC/ HRS guideline for the management of patients with atrial fibrillation: a report of the American College of Cardiology/American Heart Association Task Force on Practice Guidelines and the Heart Rhythm Society. J Am Coll Cardiol. 2014;64(21):e1-76.

3. European Heart Rhythm, Association, European Association for Cardio-Thoracic Surgery, Camm AJ, Kirchhof P, Lip GY, Schotten U, Savelieva I, et al. Guidelines for the management of atrial fibrillation: the Task Force for the Management of Atrial Fibrillation of the European Society of Cardiology (ESC). Eur Heart J. 2010;31(19):23692429.

4. Aronow WS, Banach M. Atrial Fibrillation: The new epidemic of the ageing world. J Atr Fibrillation. 2009;1(6):154.

5. Gomez-Outes A, Suarez-Gea ML, Calvo-Rojas G, Lecumberri R, Rocha E, Pozo-Hernandez C, Terleira-Fernandez AI, et al. Discovery of anticoagulant drugs: a historical perspective. Curr Drug Discov Technol. 2012;9(2):83-104.

6. Lloyd-Jones D, Adams R, Carnethon M, De Simone G, Ferguson TB, Flegal K, Ford E, et al. Heart disease and stroke statistics - 2009 update: a report from the American Heart Association Statistics Committee and Stroke Statistics Subcommittee. Circulation. 2009;119(3):480486.

7. Wolf PA, Abbott RD, Kannel WB. Atrial fibrillation as an 
independent risk factor for stroke: the Framingham Study. Stroke. 1991;22(8):983-988.

8. You JJ, Singer DE, Howard PA, Lane DA, Eckman MH, Fang MC, Hylek EM, et al. Antithrombotic therapy for atrial fibrillation: Antithrombotic Therapy and Prevention of Thrombosis, 9th ed: American College of Chest Physicians Evidence-Based Clinical Practice Guidelines. Chest. 2012;141(2 Suppl):e531S-e575S.

9. Beckman MG, Hooper WC, Critchley SE, Ortel TL. Venous thromboembolism: a public health concern. Am J Prev Med. 2010;38(4 Suppl):S495-501.

10. Dobesh PP. Economic burden of venous thromboembolism in hospitalized patients. Pharmacotherapy. 2009;29(8):943953.

11. Spencer FA, Emery C, Lessard D, Anderson F, Emani S, Aragam J, Becker RC, et al. The Worcester Venous Thromboembolism study: a population-based study of the clinical epidemiology of venous thromboembolism. J Gen Intern Med. 2006;21(7):722-727.

12. Ansell J, Hirsh J, Hylek E, Jacobson A, Crowther M, Palareti G. Pharmacology and management of the vitamin K antagonists: American College of Chest Physicians Evidence-Based Clinical Practice Guidelines (8th Edition). Chest. 2008;133(6 Suppl):160S-198S.

13. Friberg L, Hammar N, Ringh M, Pettersson H, Rosenqvist M. Stroke prophylaxis in atrial fibrillation: who gets it and who does not? Report from the Stockholm Cohortstudy on Atrial Fibrillation (SCAF-study). Eur Heart J. 2006;27(16):1954-1964.

14. Hart RG, Pearce LA, Aguilar MI. Meta-analysis: antithrombotic therapy to prevent stroke in patients who have nonvalvular atrial fibrillation. Ann Intern Med. 2007;146(12):857-867.

15. Ghadimi K, Levy JH, Welsby IJ. Prothrombin complex concentrates for bleeding in the perioperative setting. Anesth Analg. 2016;122(5):1287-1300.

16. Tomaselli GF, Mahaffey KW, Cuker A, Dobesh PP, Doherty JU, Eikelboom JW, Florido R, et al. 2017 ACC expert consensus decision pathway on management of bleeding in patients on oral anticoagulants: a report of the American college of cardiology task force on expert consensus decision pathways. J Am Coll Cardiol. 2017;70(24):30423067.

17. PatelK, Brenner BE. What is the role of dabigatran(Pradaxa) in the treatment of deep venous thrombosis (DVT)? https:// www.medscape.com/answers/1911303-23093/what-isthe-role-of-dabigatran-pradaxa-in-the-treatment-of-deepvenous-thrombosis-dvt. Accessed August 27, 2020.

18. Patel K, Brenner BE. Deep Venous Thrombosis (DVT) Treatment \& Management. https://emedicine.medscape. com/article/1911303-treatment\#d11. Accessed August 27, 2020.

19. Cuker A, Burnett A, Triller D, Crowther M, Ansell J, Van Cott EM, Wirth D, et al. Reversal of direct oral anticoagulants: Guidance from the Anticoagulation Forum. Am J Hematol. 2019;94(6):697-709.

20. Connolly SJ, Ezekowitz MD, Yusuf S, Eikelboom J, Oldgren J, Parekh A, Pogue J, et al. Dabigatran versus warfarin in patients with atrial fibrillation. N Engl J Med.
2009;361(12):1139-1151.

21. Schulman S, Kearon C, Kakkar AK, Mismetti P, Schellong $\mathrm{S}$, Eriksson H, Baanstra D, et al. Dabigatran versus warfarin in the treatment of acute venous thromboembolism. N Engl J Med. 2009;361(24):2342-2352.

22. Huisman MV, Rothman KJ, Paquette M, Teutsch C, Diener $\mathrm{HC}$, Dubner SJ, Halperin JL, et al. The changing landscape for stroke prevention in AF: findings from the GLORIAAF registry phase 2. J Am Coll Cardiol. 2017;69(7):777785.

23. Premier Healthcare Database White Paper: Data that informs and performs, March 2, 2020. Premier Applied Sciences ${ }^{\circledR}$, Premier Inc. https://learn.premierinc.com/whitepapers/premier-healthcaredatabase-whitepaper.

24. Charlson ME, Pompei P, Ales KL, MacKenzie CR. A new method of classifying prognostic comorbidity in longitudinal studies: development and validation. J Chronic Dis. 1987;40(5):373-383.

25. Deyo RA, Cherkin DC, Ciol MA. Adapting a clinical comorbidity index for use with ICD-9-CM administrative databases. J Clin Epidemiol. 1992;45(6):613-619.

26. Lane DA, Lip GY. Use of the CHA(2)DS(2)-VASc and HAS-BLED scores to aid decision making for thromboprophylaxis in nonvalvular atrial fibrillation. Circulation. 2012;126(7):860-865.

27. Pisters R, Lane DA, Nieuwlaat R, de Vos CB, Crijns HJ, Lip GY. A novel user-friendly score (HAS-BLED) to assess 1-year risk of major bleeding in patients with atrial fibrillation: the Euro Heart Survey. Chest. 2010;138(5):10931100 .

28. Lip GY, Nieuwlaat R, Pisters R, Lane DA, Crijns HJ. Refining clinical risk stratification for predicting stroke and thromboembolism in atrial fibrillation using a novel risk factor-based approach: the euro heart survey on atrial fibrillation. Chest. 2010;137(2):263-272.

29. Stangier J, Rathgen K, Stahle H, Mazur D. Influence of renal impairment on the pharmacokinetics and pharmacodynamics of oral dabigatran etexilate: an open-label, parallel-group, single-centre study. Clin Pharmacokinet. 2010;49(4):259-268.

30. Brownell KB, Sezer A, Jain S, Thoma F, Kancharla K, Aditya Bhonsale A, Saba S, et al. Trends and predictors of NOAC versus warfarin use for stroke prevention in patients with non-valvular atrial fibrillation. J Am Coll Cardiol. 2020;75(11 Supplement 1):518.

31. Desai NR, Cornutt D. Reversal agents for direct oral anticoagulants: considerations for hospital physicians and intensivists. Hosp Pract (1995). 2019;47(3):113-122.

32. Xu Y, Schulman S, Dowlatshahi D, Holbrook AM, Simpson CS, Shepherd LE, Wells PS, et al. Healthcare resource utilization and costs among patients with direct oral anticoagulant or warfarin-related major bleeding. Thromb Res. 2019;182:12-19.

33. Schiele F, van Ryn J, Canada K, Newsome C, Sepulveda E, Park J, Nar H, et al. A specific antidote for dabigatran: functional and structural characterization. Blood. 2013;121(18):3554-3562.

34. Pollack CV, Jr., Reilly PA, van Ryn J, Eikelboom JW, Glund S, Bernstein RA, Dubiel R, et al. Idarucizumab for 
dabigatran reversal - full cohort analysis. N Engl J Med. 2017;377(5):431-441.

35. Peacock WF, Rafique Z, Singer AJ. Direct-acting oral anticoagulants: practical considerations for emergency medicine physicians. Emerg Med Int. 2016;2016:1781684.

36. Yee J, Kaide CG. Emergency reversal of anticoagulation. West J Emerg Med. 2019;20(5):770-783.

37. Evans $\mathrm{G}$, Luddington R, Baglin T. Beriplex $\mathrm{P} / \mathrm{N}$ reverses severe warfarin-induced overanticoagulation immediately and completely in patients presenting with major bleeding. Br J Haematol. 2001;115(4):998-1001.

38. Heidbuchel H, Verhamme P, Alings M, Antz M, Diener HC, Hacke W, Oldgren J, et al. Updated European Heart Rhythm Association Practical Guide on the use of non-vitamin $\mathrm{K}$ antagonist anticoagulants in patients with non-valvular atrial fibrillation. Europace. 2015;17(10):1467-1507. 